\title{
The propensity to attack others as a function of the distribution of resources in a three person game
}

\author{
STEVEN G. COLE AND J. L. PHILLIPS \\ MICHIGAN STATE UNIVERSITY
}

The present study was designed to test the hypothesis that an apparently "strong" person would be disadvantaged in a three person game in which coalitions are possible. The experiment used a modified version of a truel which permitted a close examination of the interpersonal process prior to the formation of a coalition. Three conditions were studied: (1) all male Ss and no monetary payoff, (2) all female $S s$ and no monetary payoff, and (3) all female Ss and a monetary payoff. The "Strength is Weakness" effect was found under all conditions.

One of the major results of coalition formation studies has been summarized by the phrase: "Strength is Weakness," (Gamson, 1964). The present study explored this "Strength is Weakness"' phenomenon with a three person game paradigm which was designed to examine the interpersonal interaction prior to the actual formation of a coalition. This paradigm is a modified version of a truel (Shubik, 1954; Willis \& Long, 1967) in that it allows a player to attack the other players.

This paper examines the effect of the distribution of power upon the differential propensities' of group members to attack others. It was predicted that the "Strength is Weakness"' phenomenon would be observed. That is, it was predicted that the weaker group members would initiate a larger number of attacks against the strongest group member than against each other. Subjects

The Ss were 180 female and 90 male undergraduate volunteers at Michigan State University.

Procedure

The experimental paradigm consisted of each $S$ playing in a face-to-face game with two other players. To begin the game the Ss were randomly assigned as players $A, B$, or $C$, and the initial resources of each player was set by giving them a designated number of poker chips. Player A received 20 chips, Player B received 15 chips, and Player $C$ received $10 \mathrm{chips}$. The Ss were then informed that there was a payoff for the game, and that the amount that each player would receive would be determined by the number of chips he had remaining at the end of the game. The value of each chip $\left(C_{i}\right)$ would be determined by dividing the total number of chips remaining $\left(\mathrm{N}_{\mathrm{i}}\right)$ at any time (i) into the value of the payoff (V), e.g., $C_{i}=V / N_{i}$. Since $V$ was a constant, $C_{i}$ was dependent only on $N_{i}$, and the Ss were instructed that as the total number of chips decreased the value of each chip increased.
The rules of the game included a method for decreasing $\mathrm{N}_{\mathrm{i}}$. On each move a player could attack, that is, could elect to take a chip away from one of the players. On the other hand, each player had the option to pass, i.e., to refrain from attacking another player. When an attack was made, the chip was removed from the game and did not belong to any of the players. After one player had moved, the play was passed on to the next player. The order of play was completely counterbalanced with respect to initial resources.

An important feature of the game was that coalitions were allowed. Coalitions could be formed by buying or selling chips for a share of the winnings. That is, during his move, a player was allowed to offer to sell all of his chips or to buy all of another player's chips for any amount (up to the total amount of the payoff) which he chose. The player to whom the offer was made had to either accept, reject, or make a counter-offer. If he accepted the offer, the deal was completed, and the game continued as if it were a two-person game with the buyer using the combined chips of two players plus the combined power of two players, i.e., he could take away two chips on each of his remaining moves. If he rejected the offer, the game continued as if no offer had been made. If he made a counter-offer, the initial player had to accept or reject the counter-offer. If he accepted or rejected the counter-offer, the results were the same as if the initial offer had been accepted or rejected. Once an offer or counter-offer had been rejected, no more deals could be discussed during that player's move.

If at any time during a game a player lost all of his chips, he was no longer a participant. Each game ended when (1) only one player or coalition had survived, or (2) when each player had passed for five consecutive moves. In Case 1 the payoff was won by one player or was divided according to the arrangement which formed the basis for the coalition. In Case 2 each player was paid for each chip in his possession.

There were three conditions in the experiment. Two of the conditions used all female Ss and were differentiated only by the type of payoff, i.e., one condition (FM) received a $\$ 1.00$ monetary payoff and one condition (F) received a $\$ 10,000$ play money payoff. The third condition (M) was run on males who received a $\$ 10,000$ play money payoff. Ninety Ss 
were used in each condition and the rules of the game were the same for all conditions.

\section{Results and Discussion}

Analysis of the pre-coalition data revealed that virtually all Ss, regardless of experimental condition, chose to initiate an attack on each opportunity. Three separate analyses of variance computed on the data for total attacks revealed no significant difference due to sex or type of payoff. However, it was found that in all conditions $\mathrm{B}$ and $\mathrm{C}$ both attacked $\mathrm{A}$ a significantly greater number of times than they attacked each other $(p<.01)$. It was also found that there was no significant difference between the number of times $A$ attacked $B$ and the number of times $A$ attacked $C$. (See Table 1 for mean number of attacks per game and standard deviations by power, sex and type of payoff.)

To further test the "Strength is Weakness" hypothesis, a chi-square was computed on the number of times a player was attacked on the first move of the game. A "who attacked whom" matrix for initial attacks is presented in Table 2. It was found that

Table 1 Mean number of attacks per game and standard deviations by power, sex, and type of payoff

\begin{tabular}{lccccccc}
\hline & $\begin{array}{c}\text { Attacker } \\
\text { Attacked }\end{array}$ & B & C & A & C & A & B \\
\hline M & X & .87 & .90 & 1.33 & .43 & 1.00 & .37 \\
& SD & 1.49 & 1.60 & 2.48 & .89 & 1.73 & .75 \\
& & & & & & & \\
F & X & 1.80 & 1.20 & 2.48 & .83 & 1.43 & 1.23 \\
& SD & 1.68 & 1.66 & 2.92 & 1.35 & 1.78 & 1.23 \\
& & & & & & & \\
FM & X & 1.23 & 1.20 & 1.83 & .80 & 1.57 & .83 \\
& SD & 1.86 & 1.68 & 2.67 & 1.35 & 2.17 & 1.32 \\
\hline
\end{tabular}

Table 2 Who attacked whom on the initial move of the game (all experimental conditions)

\begin{tabular}{ccccr}
\hline & \multicolumn{4}{c}{ Attacked } \\
Attacker & A & B & C & \multicolumn{1}{c}{$\chi^{2}$} \\
\hline A & 0 & 13 & 6 & 2.58 \\
B & 17 & 0 & 3 & 10.32 \\
C & 16 & 4 & 0 & 7.58 \\
Total & 33 & 17 & 9 & 15.18 \\
\hline
\end{tabular}

Player A was attacked a significantly larger number of times on the initial move than either of the other two positions. It was also found that $B$ attacked $A$ initially a significantly larger number of times than $\mathrm{B}$ attacked $\mathrm{C}$ and $\mathrm{C}$ attacked $\mathrm{A}$ initially a significantly larger number of times than $\mathrm{C}$ attacked $\mathrm{B}$. There was no significant difference between the number of times $\mathrm{A}$ attacked $\mathrm{B}$ and the number of times $\mathrm{A}$ attacked $C$ on the initial move.

The "Strength is Weakness" effect was replicated in the present study and is thus extended to a truel. Furthermore it appears that the effect is operating throughout the entire coalition formation process. This is indicated because of the fact that the strongest player is attacked more than either of the other two players on the initial move as well as on all moves prior to the formation of a coalition.

\section{References}

GAMSON, W. A. Experimental studies of coalition formation. In $\mathbf{L}$. Berkowitz (Ed.), Advances in experimental social psychology. Vol. 1. New York: Academic Press, 1964.

SHUBIK, M. Does the fittest necessarily survive? In M. Shubik (Ed.), Readings in game theory and political behavior. New York: Doubleday, 1954.

WILLIS, R. H., \& LONG, NORMA JEAN. An experimental simulation of an internation truel. Behav. Sci., 1967, 12, 2432. 